\title{
Acción Inmediata de los Enjuagues Orales en la Saliva
}

\author{
Immediate Action of Mouthwashes on Whole Saliva
}

\author{
Carmen F. Vargas'; Myriam A. Koss ${ }^{1}$ \& Maria E. López ${ }^{1}$
}

VARGAS, C. F.; KOSS, M. A. \& LÓPEZ, M. E. Acción inmediata de los enjuagues orales en la saliva. Int. J. Odontostomat., 11(3):339-346, 2017.

RESUMEN: Numerosos estudios confirman la efectividad de los enjuagatorios orales sobre la viabilidad de los microorganismos que producen gingivitis y halitosis, pero poco se conoce sobre la influencia de los mismos en el medio ambiente oral. El objetivo del siguiente trabajo fue analizar In vivo e In vitro el efecto de enjuagatorios orales sobre la saliva total no estimulada. Se trabajó con saliva de individuos sanos. Para el estudio in vivo se recogieron las muestras antes y después del enjuague oral a diferentes tiempos $(1,5,10,15,30,45$ y 60 minutos). Para el ensayo in vitro, se incubó la saliva con igual volumen de la solución enjuagatoria a $37^{\circ} \mathrm{C}$ con agitación a diferentes tiempos $(1,5,10$ y 15 minutos). Se determinó $\mathrm{pH}$ inmediatamente recogidas las muestras. Posteriormente fueron centrifugadas y determinados flujo salival y proteínas totales. La separación de proteínas por electroforesis en SDS-PAGE se realizó solo en el ensayo in vivo. Los resultados mostraron que los enjuagatorios fluorurados poco alteran la fisiología oral a través de flujo salival, pH y proteínas totales. La combinación fluoruro de sodio/xilitol produjo mayor estimulación del flujo salival. La mezcla de aceites esenciales provocó un incremento del flujo salival y de $\mathrm{pH}$, redujo el contenido de proteínas totales, evidenciando por SDS-PAGE que las comprometidas fueron particularmente las de mediano y bajo peso molecular. Clorhexidina debido a su elevada sustantividad, incrementó significativamente flujo salival y $\mathrm{pH}$ in vivo. In vitro, fuera del medioambiente oral, los enjuagatorios estudiados ejercieron un efecto similar sobre proteínas totales. Los enjuagatorios de uso frecuente alteraron parámetros salivales, por lo que podría estudiarse la acción que ejercen sobre otros componentes de la saliva con actividad biológica importante en cavidad oral.

PALABRAS CLAVE: saliva, enjuages orales, gingivitis, halitosis.

\section{INTRODUCCIÓN}

La saliva posee un rol importante en el mantenimiento de los tejidos duros y blandos de la cavidad oral. En sujetos que pierden la capacidad de producir un adecuado volumen de saliva se reporta la pérdida de numerosas funciones asociadas a la saliva. Ello incluye sequedad oral (xerostomía), dificultad en la deglución de los alimentos, incremento en la susceptibilidad a infecciones oportunistas (Amerongen \& Veerman, 2002).

La saliva contiene muchos tipos de proteínas, algunas de las cuales rápidamente cubren las superficies expuestas de los tejidos duros de la cavidad oral formando la película adquirida. Algunas de estas pro- teínas, entre ellas glicoproteínas como proteínas ricas en prolina, lisozima, histatinas, amilasa y cistatinas se caracterizan por su multifuncionalidad, y están involucradas en la lubricación de la mucosa oral, en la actividad antimicrobiana, en la homeostasis del calcio, entre otras funciones (Huang, 2004).

Desde hace años se conoce que ciertos componentes de la saliva interactúan de diferentes maneras con los microorganismos de la cavidad oral controlando la composición de la microflora (Amerongen \& Veerman). Lactoperoxidasa y lisozima son ejemplos de proteínas con actividad antimicrobiana e identificadas en la película adquirida (Huang).

\footnotetext{
${ }^{1}$ Cátedra de Química Biológica, Facultad de Odontología, Universidad Nacional de Tucumán, Tucumán, Argentina. Este Trabajo fue parcialmente subvencionado por SCAIT, Código de Proyecto: J514/2. (Secretaría de Ciencia, Arte e Innovación Tecnológica), UNT y Facultad de Odontología, UNT, Argentina..
} 
Ciertos agentes presentes en enjuagues o pastas dentales son utilizados para inhibir la formación del biofilm supragingival, y para prevenir la gingivitis crónica (Eley, 1999; Huang).

La incorporación de fluoruro contribuye con la remineralización, ya que modifica la estructura del diente haciendo la superficie menos soluble al ataque de los ácidos. También reduce el metabolismo bacteriano, especialmente glucólisis, disminuyendo la producción de ácidos bacterianos (Holler et al., 2002). Una de las formas comerciales en que se presenta es en combinación con el xilitol.

Entre los alcoholes derivados de azúcares, el xilitol incorporado en gomas de mascar, aumenta flujo salival, $\mathrm{pH}$, capacidad buffer y reduce la cantidad de $\mathrm{S}$. mutans en la saliva (Ribelles Llop et al., 2010).

Los amonios cuaternarios como cloruro de cetilpiridinio, parecen ser menos efectivos en la prevención de caries y enfermedad periodontal, además de presentar baja sustantividad y reportarse algunos efectos secundarios como manchas y sensación de quemazón (Eley).

El triclosán (éter 2,4,4-tricloro-2-hidroxidifenilo), es un agente antimicrobiano fenólico, de naturaleza hidrofóbica. Posee efectiva acción antifúngica, antiinflamatoria y anticancerígena, baja toxicicidad y baja incidencia de sensibilización por contacto (Hoq et al., 2008).

La mezcla de aceites esenciales constituida por timol, eucaliptol, salicilato de metilo y mentol, es usada en la industria farmacéutica como enjuague oral. En presencia de este enjuagatorio, no se observa incremento en los patógenos orales putativos y/o oportunistas. Similares resultados se obtienen con enjuague de clorhexidina (Santos, 2003).

La clorhexidina tiene gran afinidad por las superficies de los tejidos duros y blandos y por ello se deposita después del enjuague o la irrigación. Debido a su alta sustantividad se considera el "gold standard» de los antisépticos (Santos).

En La búsqueda de agentes para el control de la placa es necesario considerar la influencia que los mismos tienen sobre la saliva, agente promotor de la homeostasis del ambiente oral.

Por lo tanto, el objetivo de este estudio es eva- luar In vivo e In vitro la acción ejercida por los enjuagatorios orales sobre flujo salival, $\mathrm{pH}$ y proteínas de la saliva total no estimulada.

\section{MATERIAL Y MÉTODO}

Individuos. El estudio incluyó 6 individuos con edades comprendidas entre 28 a 47años, todos ellos con buen estado de salud oral, sin signos de gingivitis 0 periodontitis (profundidad de sondaje $\leq 3 \mathrm{~mm}$ ) y ausencia de caries activa, un mínimo de 20 dientes, al menos 5 por cada cuadrante y ausencia de lesiones orales. El estado de salud fue evaluado por un examinador odontólogo calibrado.

Los criterios de exclusión fueron: consumo de tabaco, presencia de prótesis o artefacto ortodóncico, tratamiento con antibióticos, uso de rutina de algún antiséptico oral o cualquier medicamento que pudiera alterar la composición o producción de saliva.

Recolección de Saliva. Los pacientes fueron instruidos a no comer ni beber al menos $2 \mathrm{~h}$ previas a la recolección de la muestra de saliva. La misma obtenida en todos los sujetos entre las 8:00 am y 10:00 am. Las muestras de saliva no estimulada recolectadas durante $30 \mathrm{~s}$ por salivación en tubos refrigerados. El procedimiento fue repetido por todos los sujetos para cada enjuagatorio, estableciendo un lapso de 2 semanas entre uno y otro.

Enjuagatorios. Se utilizaron 6 enjuagatorios: Fluoruro de Sodio 0,05 \% / Cloruro de Cetilpiridinio $0.05 \%$ (FC1) pH: 7,03; Fluoruro de Sodio 0,05 \% / Triclosan 0,03 \% / Gantrez 0,02\% (FTG2) pH: 6,75; Fluoruro de Sodio 0,05 $\%$ / Xilitol $10 \%$ (Naf Buches $^{\circledR}$ ) (FX3) pH: 6,71; Fluoruro de Sodio 0,05 \% - Cloruro de Cetilpiridinio 0,05\% (FCC4) pH: 6,29; Mentol 0,04 \% / Timol 0,06 \% / Eucaliptol 0,09 $\%$ b/Metil salicilato $0,06 \%$ (EA5) $\mathrm{pH}: 4,12$ y Digluconato de Chlorhexidina 0,12\% (Periobacter ${ }^{\circledR}$ ) (ChX6) pH: 6,68. En el ensayo In vitro, para la mezcla de aceites esenciales el pH fue ajustado a 7 con $\mathrm{NaOH} 0,5 \mathrm{~N}$. Tanto en el ensayo In vivo como In vitro se usó agua destilada como control (C).

Ensayo In vivo. Se recolectó saliva no estimulada de cada paciente y luego se le pidió que realizara buches con el enjuagatorio durante $30 \mathrm{~s}$. Se extrajeron muestras de saliva no estimulada a 1, 5, 10, 15, 30, 45, 60 min. El mismo procedimiento se siguió para $\mathrm{C}$. Las muestras se centrifugaron a $10.000 \mathrm{rpm}, 10 \mathrm{~min}$ a $4^{\circ} \mathrm{C}$ y se 
mantuvieron a $-20^{\circ} \mathrm{C}$ hasta su posterior análisis.

Ensayo In vitro. Se mezclaron $200 \mu$ de saliva total no estimulada con $200 \mu \mathrm{l}$ de cada enjuagatorio y se incubaron a $37^{\circ} \mathrm{C}$ con rotación manual durante $1,5,10$ y 15 min. Se centrifugaron a $10000 \mathrm{rpm} 10 \mathrm{~min}$ a $4{ }^{\circ} \mathrm{C}$. El sobrenadante almacenado a $-20^{\circ} \mathrm{C}$ hasta su posterior procesamiento.

Determinaciones. El pH de cada muestra fue determinado inmediatamente después de su recolección con pHmetro digital (Broadley-James Corp. Irvine, California, USA). El volumen de saliva recolectada en $30 \mathrm{~s}$ fue medido y luego se calculó el flujo salival expresado en $\mathrm{mL} /$ min. El contenido de proteínas totales en cada muestra fue determinado usando el método de Lowry et al. (1951).

Electroforesis SDS-PAGE. Realizado solo en el ensayo In vivo con el fin de evaluar la respuesta fisiológica glandular. Para ello las muestras de saliva fueron filtradas usando membranas de policarbonato (Whatman, Maidstone, UK). Luego suspendidas en buffer de muestra conteniendo glicerol, 2-mercapto etanol, SDS y azul de bromo fenol y desnaturalizadas por calentamiento a $95^{\circ} \mathrm{C}$ por 5 min. Las muestras fueron analizadas por SDS - PAGE descripto por Laemmli (1970), usando geles de corrida y de staking al $12,5 \%$ y al $4 \%$ respectivamente. Luego los geles fijados y coloreados con una solución de Coomassie Brilliant Blue R-250 0,1 \% (Gorg et al., 1985).

Análisis Estadístico. Las diferencias estadísticamente significativas de los promedios de los valores de los parámetros salivales fueron analizadas mediante Análisis de la Varianza (ANOVA). Para la regresión lineal se consideró una distribución normal de cada parámetro. Los datos fueron analizados con el programa SPSS.

\section{RESULTADOS}

Ensayo In vivo. La acción de los enjuagatorios sobre el flujo salival se muestra en la Figura 1. FX3, EA5 y ChX6 ejercen incrementos significativos $(p<0,005)$ respecto a $\mathrm{C}$ en los primeros $15 \mathrm{~min}$, mientras que con $\mathrm{ChX} 6$, dicho incremento se mantiene en todos los tiempos estudiados. FTG2 y FCC4 muestran incrementos significativos a los 10 min el primero, y el segundo a 1 y 5 min $(p<0,05)$. FC1 sigue un comportamiento similar a $C$, sin cambios significativos respecto al estado basal $(p>0,05)$.

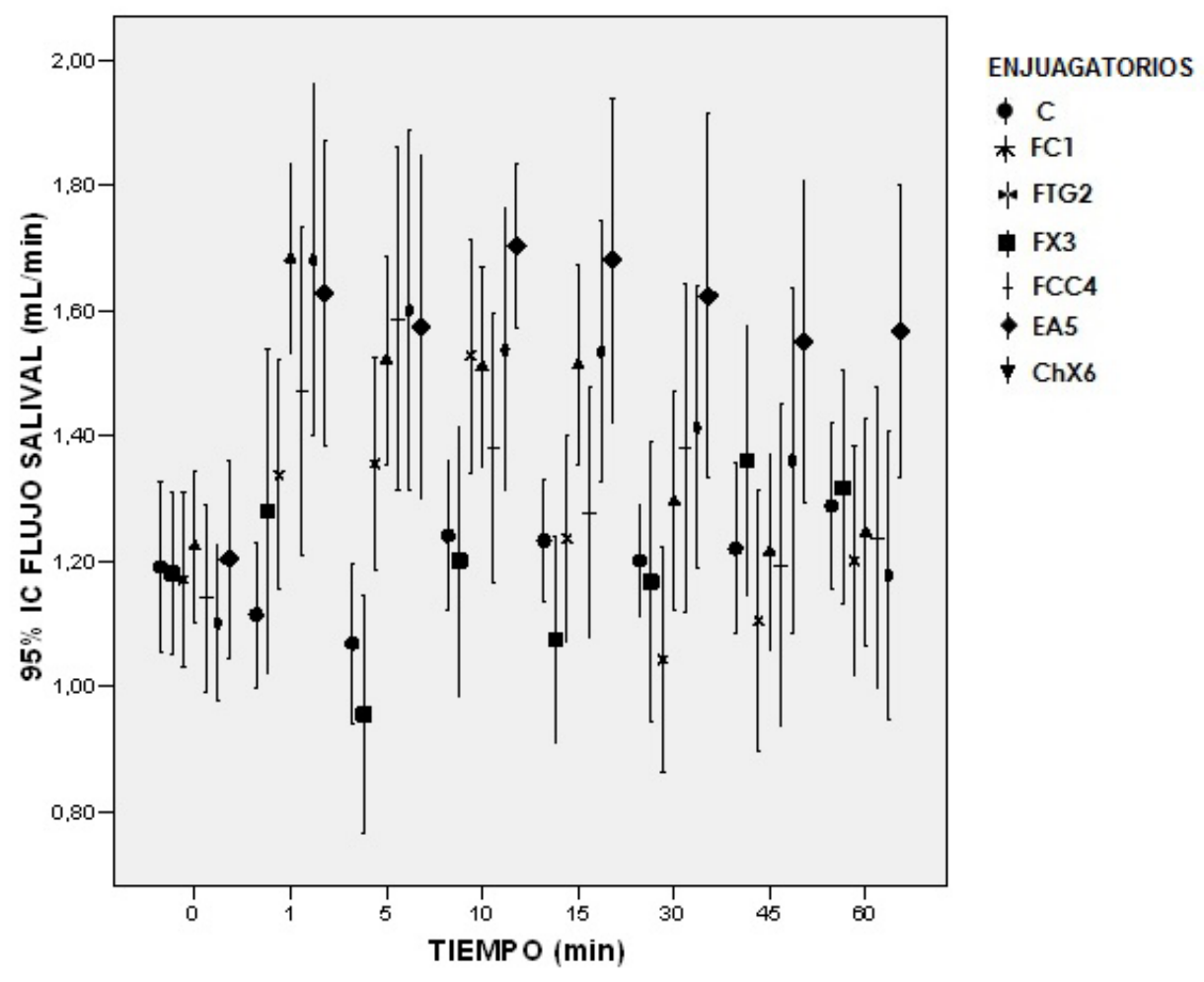

Fig. 1. Acción in vivo de los enjuagatorios sobre el flujo salival. 
En cuanto al pH (Fig. 2), todos los enjuagatorios lo incrementan significativamente a 1 min $(p<0,005)$. FTG2 retoma los valores basales a 5 min, FCC1, FX3 y FCC4 a 10 min, EA5 a 15 min, mientras que ChX6 mantiene niveles significativamente incrementados $(p<0,001)$ hasta 30 min respecto del estado basal. C no muestra diferencias en ninguno de los tiempos estudiados $(p>0,05)$.

La Figura 3 muestra que los enjuagatorios a base de fluoruro de sodio FCC1, FTG2 y FCC4 y ChX6 no influyen de manera significativa sobre las proteínas salivales. $\mathrm{FX} 3$ produce una disminución significativa $(p<0,01)$ respecto a los datos basales hasta 5 min $(p<0,005)$ y EA5 entre 5 y $30 \mathrm{~min}(p<0,000)$.

Al analizar proteínas totales por SDS - PAGE obtenidas luego del enjuague C (Fig. 4a), las bandas presentes en todos los tiempos corresponden a $6,20,45,50,66,90,100$ y 200 kDa. Además, puede observarse una banda de alrededor de $70 \mathrm{kDa}$, que desaparece a partir de los $45 \mathrm{~min}$.

Con FCC1 (Fig. 4b), se distinguen bandas de peso molecular a 6, 20, 45, 50, 66, 70 y $90 \mathrm{kDa}$. La intensidad de todas las bandas hasta los 5 min es menor que las observadas en los otros tiempos. Pue- de observarse una banda a $200 \mathrm{kDa}$ que va intensificándose a partir de los 15 min. Con FGT2 (Fig. 4c) el comportamiento de las proteínas sigue un perfil electroforético similar al del C (Fig. 4a). En presencia de FX3 (Fig. 4d), las bandas de peso molecular 90,100 y $200 \mathrm{kDa}$ solo son evidentes a los 15 y 60 $\mathrm{min}$. Las de peso molecular inferior a $90 \mathrm{kDa}$ son coincidentes con las de $\mathrm{C}$ a todos los tiempos estudiados. En la Fig. 4e (FCC4), todas las bandas se presentan difusas, se observa solo ausencia de la banda de $100 \mathrm{kDa}$. La intensidad de todas las bandas hasta 5 min es menor que las observadas en los otros tiempos.

En la Fig. 4f, se evidencia que el enjuagatorio EA5 ejerce una marcada disminución de intensidad de todas las bandas, en especial de las de bajo peso molecular.

El enjuagatorio ChX6 (Fig. 4g), ejerce un efecto similar al del C.

Ensayo In vitro. Los valores de proteínas registrados son inferiores al del dato basal durante el ensayo con todos los enjuagatorios (Fig. 5), siendo notoriamente menor $(p<0,000)$ con el enjuagatorio EA5.

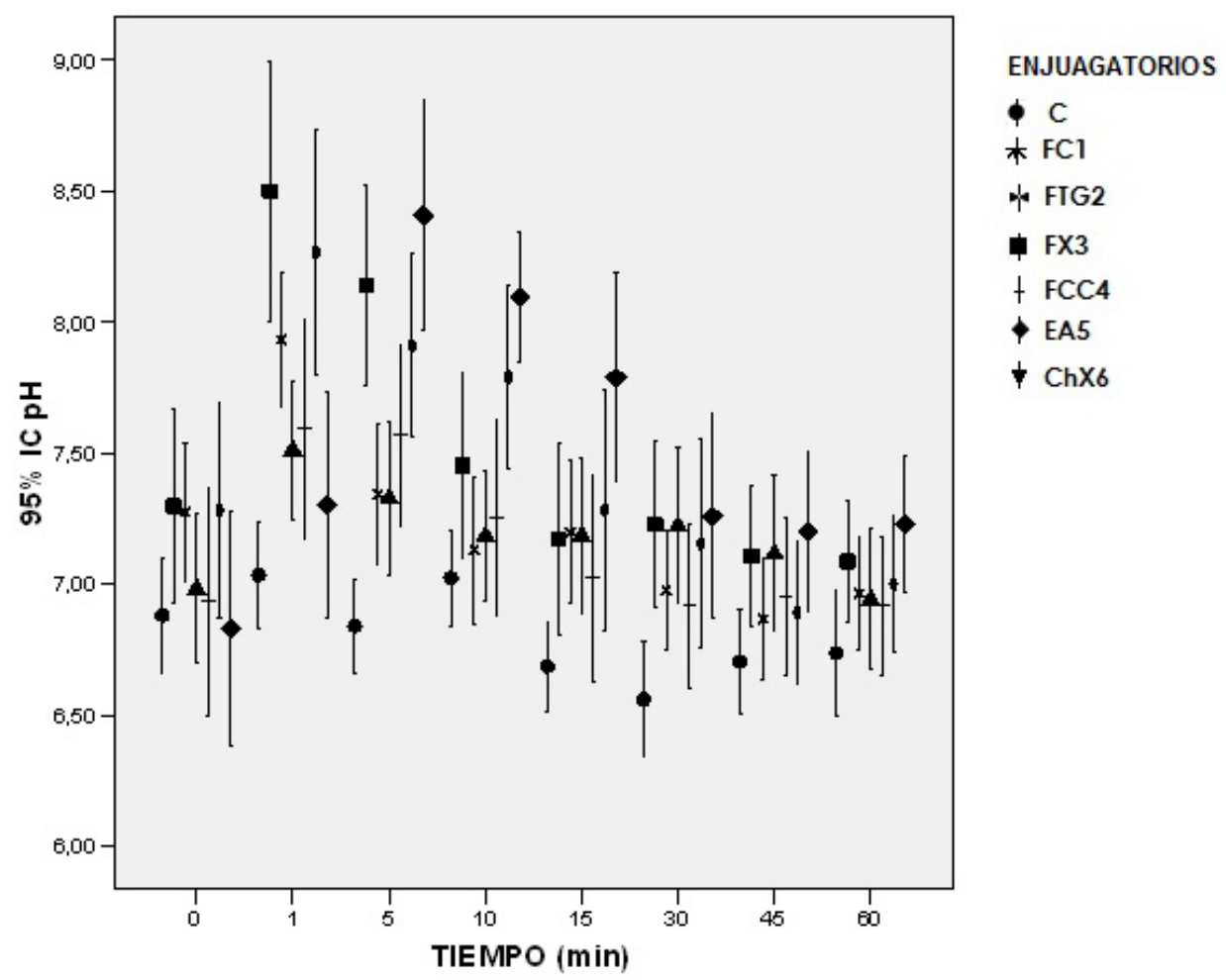

Fig. 2. Acción in vivo de los enjuagatorios sobre $\mathrm{pH}$ salival. 


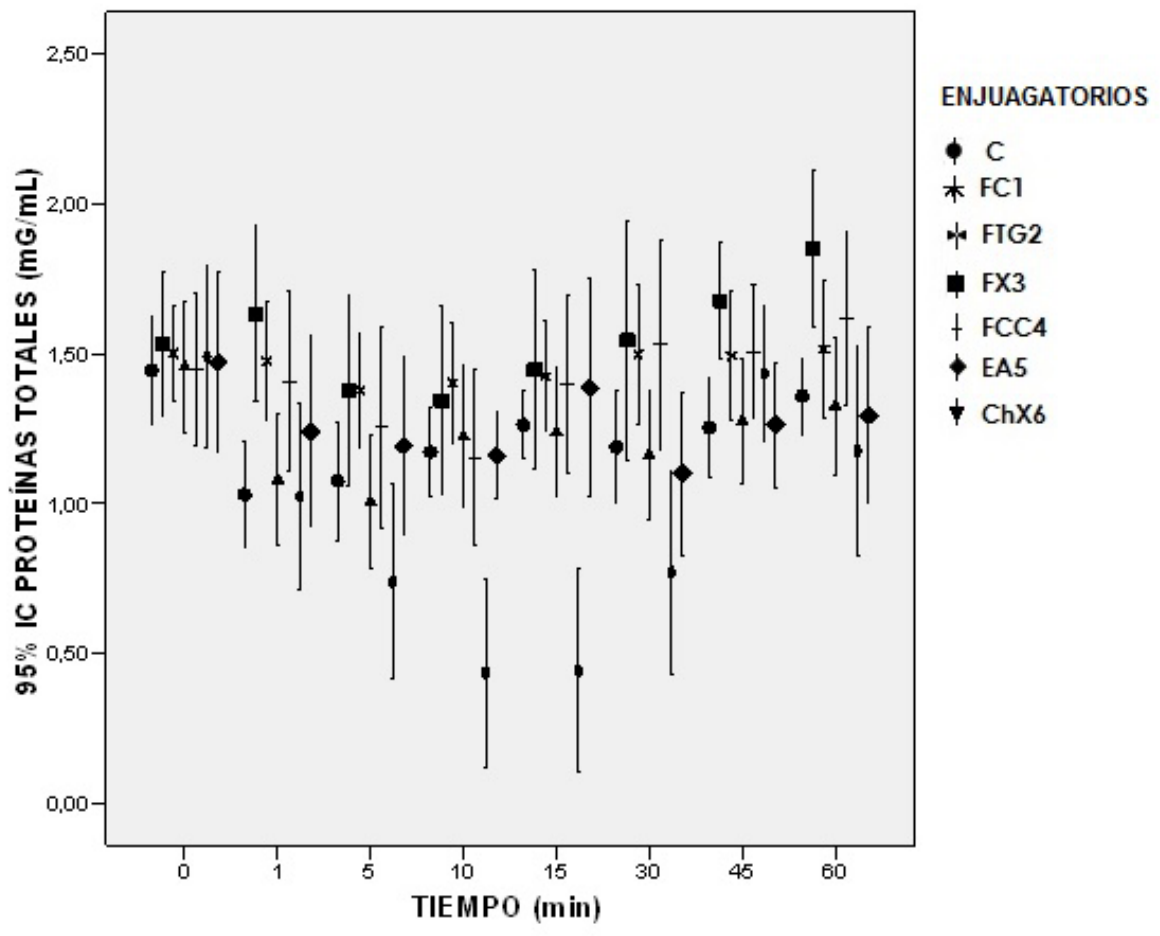

Fig. 3. Acción in vivo de los enjuagatorios sobre las proteínas totales
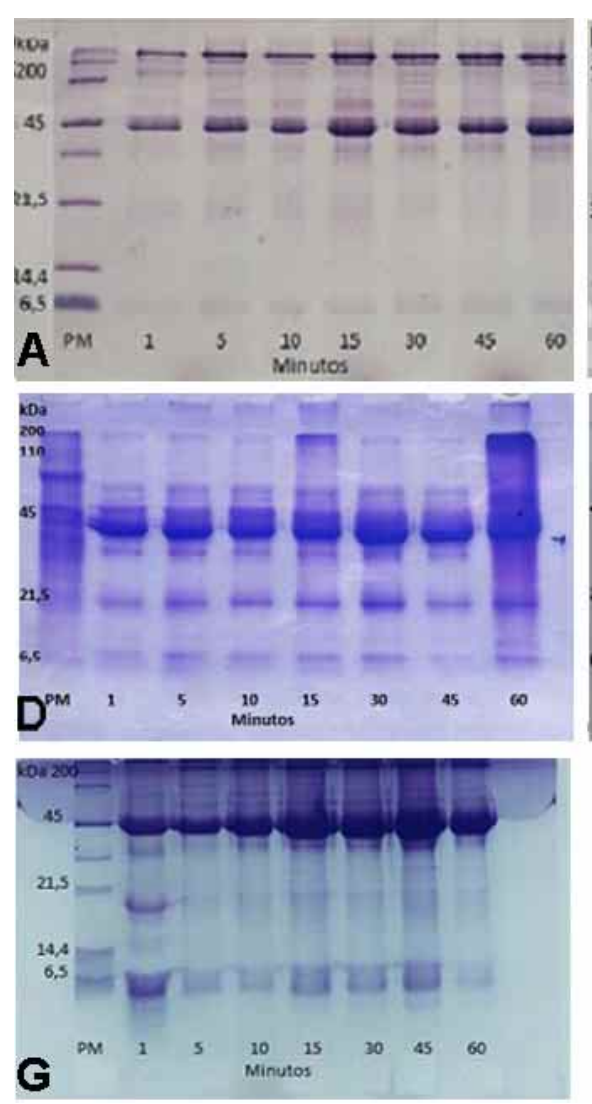
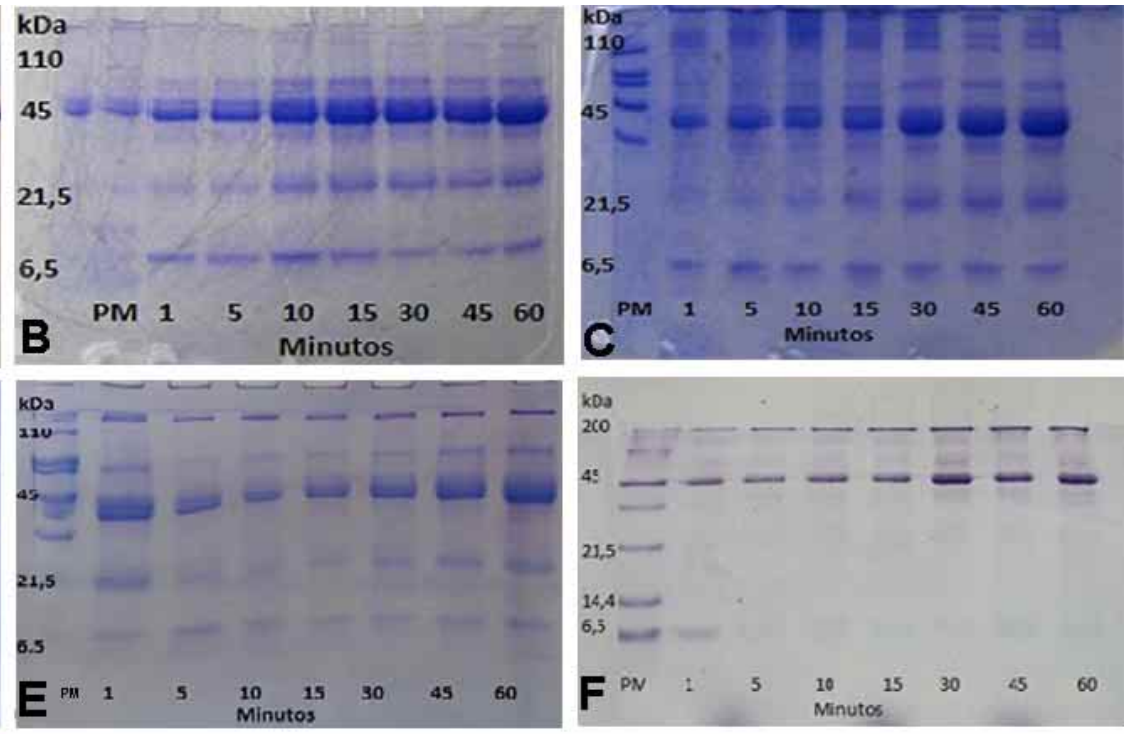

Fig. 4a. SDS - PAGE de la acción In vivo del agua destilada (C) sobre las proteínas salivales. 4b. SDS - PAGE de la acción In vivo del enjuagatorio FCC1 sobre las proteínas salivales. 4c. SDS - PAGE de la acción In vivo del enjuagatorio FGT2 sobre las proteínas salivales. 4d. SDS - PAGE de la acción In vivo del enjuagatorio FX3 sobre las proteínas salivales. 4e. SDS - PAGE de la acción in vivo del enjuagatorio FCC4 sobre las proteínas salivales. 4f. SDS PAGE de la acción In vivo del enjuagatorio EA5 sobre las proteínas salivales. 4 g. SDS - PAGE de la acción In vivo del enjuagatorio ChX6 sobre las proteínas salivales. 


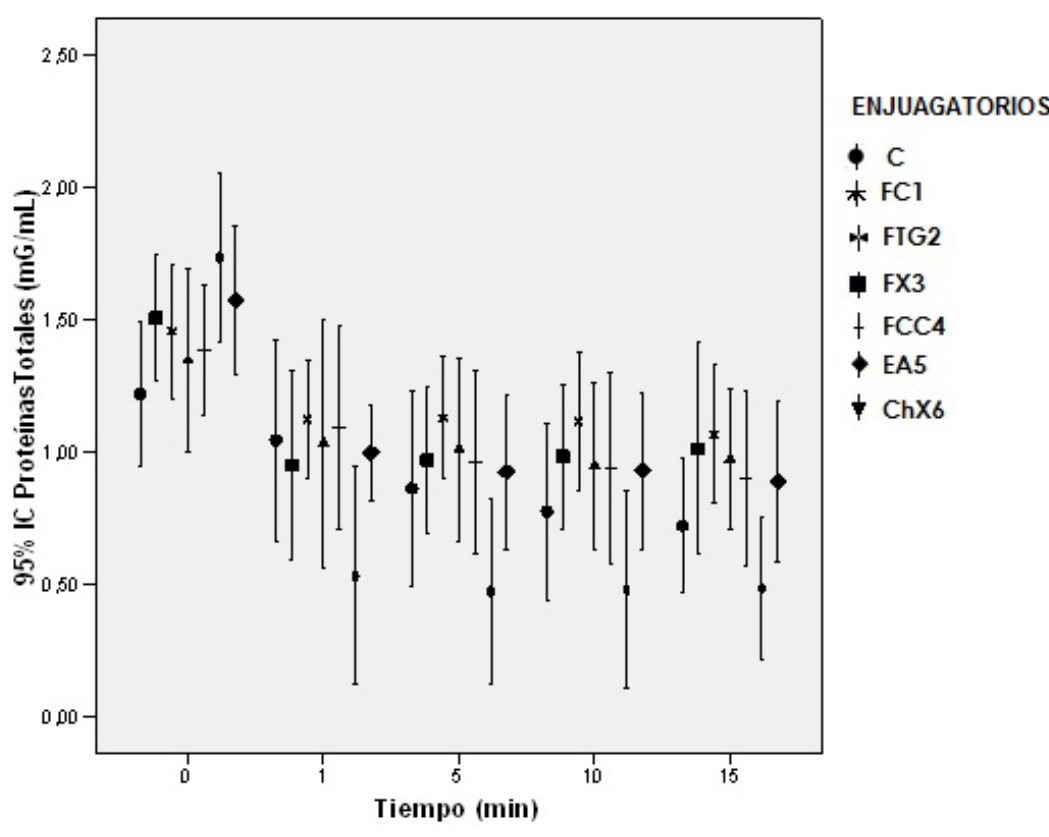

Fig. 5. Acción in vitro de los enjuagatorios sobre las proteínas totales

\section{DISCUSION}

La saliva es esencial para el mantenimiento de la salud oral, participa en la homeostasis de la cavidad oral, en la lubricación de los tejidos y en las funciones de masticación, habla y deglución. Además, al estar en contacto con los tejidos duros y blandos del diente los protege de agentes extraños, como bacterias y virus (Yan et al., 2009; Koscielniak et al., 2012). En situaciones fisiológicas, dichas funciones, están condicionadas por el flujo salival y la duración del estímulo, que influyen a su vez en el pH y la composición de la saliva. Así, con excepción de fosfato y magnesio que disminuyen al incrementarse el flujo salival, la mayoría de los otros constituyentes salivales se elevan (Jenking, 1983).

La higiene a través del cepillado y del uso del hilo dental promueve la eliminación mecánica del biofilm contribuyendo a la prevención de la caries dental y la enfermedad periodontal. Si estas acciones se complementan con el uso de agentes antimicrobianos incorporados en dentífricos, enjuagues orales o barnices, se logra una potenciación de los procedimientos de higiene mecánica (Bascones \& Morante, 2006).

Los resultados del presente trabajo evidencian que los enjuagatorios a base de fluoruros ejercen poca influencia sobre el flujo salival, excepto cuando están combinados con xilitol. Milgrom et al. (2006), consideran al xilitol como estimulante de la secreción salival, lo cual es un factor importante en el mantenimiento del $\mathrm{pH}$ salival, además que favorece el barrido mecánico de las superficies de los dientes. Riedy et al. (2008) señalan que además de dichas propiedades, el xilitol ejerce un efecto de remineralización en los sitios descalcificados de los dientes y una reducción cuantitativa del biofilm y/o de la población de $S$. mutans. Al inhibir el fluoruro, a las fosfatasas y pirofosfatasas bacterianas, enzimas promotoras de la formación de cálculos, el uso de estos enjuagatorios contribuiría a disminuir tal formaciónfavoreciendo la mineralización del esmalte y dentina (Zhi et al., 2013). Las proteínas salivales no evidencian cambios significativos con el uso de enjuagatorios fluorados por lo cual la homeostasis del medio buco - dental no se alteraría, contribuyendo a la integridad de los tejidos.

EA5 es el enjuagatorio que mayor influencia ejerce sobre las variables estudiadas. El incremento de flujo salival y $\mathrm{pH}$ en este enjuagatorio en los primeros minutos, probablemente sea consecuencia de un mecanismo compensatorio debido a la presencia del buffer ácido cítrico/ citrato (responsable del bajo pH 4,12 de este enjuagatorio). Los alcoholes del mismo provocan una disminución muy marcada de proteínas totales In vivo; que se mantiene hasta los $30 \mathrm{~min}$. In vitro, esta disminución es muy evidente en todos los tiempos respecto de los datos basales. Estos resultados conducen a concluir que la formulación del enjuagatorio rico en alcoholes y ácidos, produce la desnaturalización e insolubilización de proteínas. Estos hallazgos se confirman por electroforesis, donde se observa In vivo, una disminución en la intensidad de todas las bandas de proteínas presentes. Según Yan et al., las proteínas de mediano y bajo peso molecular corresponderían a amilasa, proteínas ricas en prolina, lisozima y estaterinas, las cuales cumplen funciones de defensa, limpieza de las superficies orales expuestas y formación de película adquirida. Las proteínas de elevado peso molecular corresponderían a las mucinas que protegen las mucosas formando una barrera contra estímulos nocivos como toxinas microbianas, comportándose como un factor 
humectante y de mantenimiento de las células que conforman el revestimiento oral (Sonesson et al., 2008). Nuestros resultados coincidirían con los de Kuyama \& Yamamoto (1997), quienes evidenciaron un efecto irritante sobre la mucosa por alcoholes fenolados. Observan en células de la mucosa oral, que un elevado contenido de etanol, bajo $\mathrm{pH}$ y otros ingredientes de enjuagatorios con alcoholes fenolados, tenderían a provocar cambios en las proteínas nucleares y citoplasmáticas. Además, Haq et al. (2009), demostraron que el etanol presente en su formulación, por encima del $25 \%$, aumenta la permeabilidad de la mucosa oral, favoreciendo el ingreso de carcinógenos a través de la mucosa.

ChX6, incrementa significativamente el flujo salival en todos los tiempos estudiados, lo que incidiría en la depuración de las bacterias en fase planctónicas de la cavidad oral. Tal incremento se puede atribuir a su elevada sustantividad y a la presencia del xilitol en su formulación (Milgrom et al.). Referido a clorhexidina, numerosos estudios (Eley; Bascone \& Morante, 2006; Tsuchiya et al., 1999; Musteata \& Pawliszyn, 2005) demuestran su permanencia en la cavidad oral después de $12 \mathrm{~h}$ de realizar buches durante $60 \mathrm{~s}$ con soluciones $0,12 \%$. La molécula de clorhexidina es fuertemente catiónica con afinidad por las superficies cargadas negativamente, entre ellas células epiteliales, esmalte y proteínas salivales, a partir de las cuales va liberándose lentamente (Shrestha et al., 2011). De todos los enjuagatorios estudiados, éste ejerce un efecto más prolongado sobre el aumento de $\mathrm{pH}$ lo cual favorecería el proceso de remineralización del esmalte. Sin embargo, numerosos estudios hacen referencia de la tendencia de clorhexidina a contribuir con la formación de cálculos supragingivales (Eley; Kumar et al., 2013; Calderini et al., 2013). La leve disminución de proteínas In vivo $(p>0,05)$ entre 5 y 10 min, sumado a la presencia de tenues bandas de proteínas de peso molecular inferior a $66 \mathrm{kDa}$ observadas por SDS - PAGE, llevan a postular que clorhexidina, debido a su carácter catiónico, tiende a formar complejos insolubles con proteínas aniónicas como albúmina y mucinas, las que se encuentran dentro del rango de peso molecular mencionado (Tsuchiya et al.; Musteata \& Pawliszyn). Referido a esto, Tsuchiya et al. sostienen que estas proteínas son responsables de la adsorción de la clorhexidina a la superficie del esmalte y de células epiteliales, comportándose como reservorios a partir de los cuales va liberándose lentamente. Para Musteata \& Pawliszyn, la precipitación de clorhexidina con proteínas de elevado peso molecular, podría in- fluenciar en la composición del film salival y en la adhesión y coagregación bacteriana.

Del este estudio se desprende que In vivo, los enjuagues a base de fluoruros tienen muy bajo efecto sobre las variables salivales estudiadas. Los enjuagatorios EA5 alteran todas las variables, incrementan flujo salival, $\mathrm{pH}$ y disminuyen proteínas totales, sobre todo las de bajo y mediano peso molecular. ChX6 eleva flujo salival todo el ensayo, eleva $\mathrm{pH}$, no afectando la composición proteica. In vitro, los enjuagatorios estudiados disminuyeron proteínas totales.

Estudios posteriores podrían analizar la influencia de estos enjuagatorios sobre los iones y otros componentes orgánicos de la saliva y los mecanismos de acción con que operan en cada caso.

VARGAS, C. F.; KOSS, M. A. \& LÓPEZ, M. E. Immediate action of mouthwashes on whole saliva. Int. J. Odontostomat., 11(3):339-346, 2017.

ABSTRACT: Numerous studies confirm the effectiveness of mouthwashes on the viability of microorganisms that produce gingivitis and halitosis, but little is known about their influence on the oral environment. The objective of the following work was to analyze In vivo and In vitro the effect of mouthwashes on total non-stimulated saliva. We worked with saliva from healthy individuals. For In vivo study, samples were collected before and after oral rinsing at different times $(1,5,10,15,30,45$ and 60 minutes). For the $I n$ vitro assay, the saliva was incubated with equal volume of the rinse solution at $37^{\circ} \mathrm{C}$ with shaking at different times (1, 5, 10 and 15 minutes). PH was determined immediately collected samples. Subsequently they were centrifuged and determined salivary flow and total proteins. Separation of proteins by SDS-PAGE electrophoresis was performed only in the In vivo assay. The results showed that fluoridated rinses hardly alter oral physiology through salivary flow, $\mathrm{pH}$ and total proteins. The combination of sodium fluoride / xylitol produced greater stimulation of salivary flow. The mixture of essential oils caused an increase in salivary flow and $\mathrm{pH}$, reduced the total protein content, evidencing by SDS-PAGE that those involved were particularly those of medium and low molecular weight. Chlorhexidine due to its high substantivity, significantly increased salivary flow and $\mathrm{pH}$ In vivo. In vitro, outside the oral environment, the rinses studied had a similar effect on total proteins. Rinses used frequently altered 
salivary parameters, so that the action they exert on other components of saliva with important biological activity in the oral cavity could be studied.

\section{proteins.}

KEY WORDS: saliva, mouthrinse, salivary

\section{REFERENCIAS BLIOGRÁFICAS}

Amerongen, A. V. \& Veerman, E. C. Saliva--the defender of the oral cavity. Oral Dis., 8(1):12-22, 2002.

Bascones, A. \& Morante, S. Antisépticos orales. Revisión de la literatura y perspectiva actual. Av. Periodoncia., 18(1):21-9, 2006.

Calderini, A.; Pantaleo, G.; Rossi, A.; Gazzolo, D. \& Polizzi, E. Adjunctive effect of chlorhexidine antiseptics in mechanical periodontal treatment: first results of a preliminary case series. Int. J. Dent. Hyg., 11(3):180-5, 2013.

Eley, B. M. Antibacterial agents in the control of supragingival plaque-a review. Br. Dent. J., 186(6):286-96, 1999.

Gorg, A.; Postel, W.; Weser, J.; Schiwara, H. W. \& Boesken, W. H. Horizontal SDS electrophoresis in ultrathin pore-gradient gels for the analysis of urinary proteins. Sci. Tools, 32:5-9, 1985.

Haq, M. W.; Batool, M.; Ahsan, S. H. \& Qureshi, N. R. Alcohol use in mouthwash and possible oral health concerns. J. Pak. Med. Assoc., 59(3):186-90, 2009.

Holler, B. E.; Friedl, K. H.; Jung, H.; Hiller, K. A. \& Schmalz, G. Fluoride uptake and distribution in enamel and dentin after application of different fluoride solutions. Clin. Oral Investig., 6(3):137-44, 2002.

Hoq, M. I.; Mitsuno, K.; Tsujino, Y., Aoki, T. \& Ibrahim, H. R. Triclosanlysozyme complex as novel antimicrobial macromolecule: a new potential of lysozyme as phenolic drug-targeting molecule. Int. J. Biol. Macromol., 42(5):468-77, 2008.

Huang, C. M. Comparative proteomic analysis of human whole saliva. Arch. Oral Biol., 49(12):951-62, 2004.

Jenkins, G. N. Fisiología y Bioquímica Oral. Ciudad de México, Limusa, 1983. pp.301-432.

Koscielniak, D.; Jurczak, A.; Zygmunt, A. \& Krzysciak, W. Salivary proteins in health and disease. Acta Biochim. Pol., 59(4):451-7, 2012.

Kumar, S.; Patel, S.; Tadakamadla, J.; Tibdewal, H.; Duraiswamy, P. \& Kulkarni, S. Effectiveness of a mouthrinse containing active ingredients in addition to chlorhexidine and triclosan compared with chlorhexidine and triclosan rinses on plaque, gingivitis, supragingival calculus and extrinsic staining. Int. J. Dent. Hyg., 11(1):35-40, 2013.

Kuyama, K. \& Yamamoto, H. A study of effects of mouthwash on the human oral mucosae: with special references to sites, sex differences and smoking. J. Nihon Univ. Sch. Dent., 39(4):20210, 1997.

Laemmli, U. K. Cleavage of structural proteins during the assembly of the head of bacteriophage T4. Nature, 227(5259):680-5, 1970.

Lowry, O. H.; Rosebrough, N. J.; Farr, A. L. \& Randall, R. J. Protein measurement with the Folin phenol reagent. J. Biol. Chem., 193(1):265-75, 1951.

Milgrom, P.; Ly, K. A.; Roberts, M. C.; Rothen, M.; Mueller, H. \& Yamaguchi, D. K. Mutans streptococci dose response to xylitol chewing gum. J. Dent. Res., 85(2):177-81, 2006.

Musteata, F. M. \& Pawliszyn, J. Assay of stability, free and total concentration of chlorhexidine in saliva by solid phase microextraction. J. Pharm. Biomed. Anal., 37(5):1015-24, 2005.

Ribelles Llop, M.; Guinot Jimeno, F.; Mayné Acién, R. \& Bellet
Dalmau, L. J. Effects of xylitol chewing gum on salivary flow rate, $\mathrm{pH}$, buffering capacity and presence of Streptococcus mutans in saliva. Eur. J. Paediatr. Dent., 11(1):9-14, 2010.

Riedy, C. A.; Milgrom, P.; Ly, K. A.; Rothen, M.; Mueller, G.; Hagstrom, M. K.; Tolentino, E.; Zhou, L. \& Roberts, M. C. A surrogate method for comparison analysis of salivary concentrations of Xylitolcontaining products. B. M. C. Oral Health, 8:5, 2008.

Santos, A. Evidence-based control of plaque and gingivitis. J. Clin. Periodontol., 30 Suppl. 5:13-6, 2003.

Shrestha, A.; Rimal, J.; Rao, A.; Sequeira, P. S.; Doshi, D. \& Bhat, G. K. In vitro antifungal effect of mouth rinses containing chlorhexidine and thymol. J. Dent. Sci., 6(1):1-5, 2011.

Sonesson, M.; Wickström, C.; Kinnby, B.; Ericson, D. \& Matsson, L. Mucins MUC5B and MUC7 in minor salivary gland secretion of children and adults. Arch. Oral Biol., 53(6):523-7, 2008.

Tsuchiya, H.; Miyazaki, T. \& Ohmoto, S. High-performance liquid chromatographic analysis of chlorhexidine in saliva after mouthrinsing. Caries Res., 33(2):156-63, 1999.

Yan, W.; Apweiler, R.; Balgley, B. M.; Boontheung, P.; Bundy, J. L.; Cargile, B. J.; Cole, S.; Fang, X.; Gonzalez-Begne, M.; Griffin, T. J.; Hagen, F.; Hu, S.; Wolinsky, L. E.; Lee, C. S.; Malamud, D.; Melvin, J. E.; Menon, R.; Mueller, M.; Qiao, R.; Rhodus, N. L.; Sevinsky, J. R.; States, D.; Stephenson, J. L.; Than, S.; Yates, J. R.; Yu, W.; Xie, H.; Xie, Y.; Omenn, G. S.; Loo, J. A. \& Wong, D. $\mathrm{T}$. Systematic comparison of the human saliva and plasma proteomes. Proteomics Clin. Appl., 3(1):116-34, 2009.

Zhi, Q. H.; Lo, E. C. \& Kwok, A. C. An In vitro study of silver and fluoride ions on remineralization of demineralized enamel and dentine. Aust. Dent. J., 58(1):50-6, 2013.

Correspondence author

Vargas Carmen Fátima

Department of Biochemistry

Faculty of Dentistry

National University of Tucumán

Av. Benjamín Aráoz 800

Tucumán

ARGENTINA

E-mail: carmenf_vargas@hotmail.com

Recibido : 15-05-2017

Aceptado: 19-06-2017 